\title{
Adipose tissue fatty acids and insulin sensitivity in elderly men
}

\author{
D. Iggman • J. Ärnlöv • B. Vessby • T. Cederholm • \\ P. Sjögren • U. Risérus
}

Received: 10 December 2009 / Accepted: 22 December 2009/Published online: 3 February 2010

(C) Springer-Verlag 2010

\begin{abstract}
Aims/hypothesis Dietary fatty acids may affect insulin sensitivity. Adipose tissue fatty acid composition partly reflects long-term dietary intake, but data from large studies regarding relationships with insulin sensitivity are lacking. We aimed to determine the association between adipose tissue fatty acids and insulin sensitivity in elderly Swedish men.

Methods In a cross-sectional analysis of the communitybased Uppsala Longitudinal Study of Adult Men $(n=795$, mean age 71 years), adipose tissue biopsies were obtained and fatty acid composition was determined by gas-liquid chromatography. Insulin sensitivity was measured directly by a euglycaemic clamp.

Results Palmitic acid (16:0), the major saturated fatty acid (SFA) in the diet and in adipose tissue, was negatively correlated with insulin sensitivity $(r=-0.14)$, as were 16:1 $n-7 \quad(r=-0.15), 20: 3 n-6 \quad(r=-0.31), 20: 4 n-6 \quad(r=-0.38)$, 22:4 $n-6(r=-0.37)$ and 22:5 $n-3(r=-0.24 ; p<0.001$ for all).
\end{abstract} Some minor SFAs were positively correlated; 12:0 $(r=0.46)$,

D. Iggman • B. Vessby • T. Cederholm • P. Sjögren • U. Risérus

Department of Public Health and Caring Sciences,

Clinical Nutrition and Metabolism, Uppsala University,

Uppsala, Sweden

D. Iggman

Center for Clinical Research Dalarna,

Falun, Sweden

J. Ärnlöv

Department of Health and Social Sciences, Högskolan Dalarna,

Falun, Sweden

U. Risérus $(\square)$

Clinical Nutrition and Metabolism, Uppsala Science Park,

75185 Uppsala, Sweden

e-mail: ulf.riserus@pubcare.uu.se
14:0 $(r=0.32), 17: 0(r=0.21)$ and 18:0 $(r=0.41 ; p<0.001$ for all), as were essential polyunsaturated fatty acids (PUFAs) 18:2 $n-6(r=0.10, p<0.01)$ and 18:3 $n-3(r=0.16, p<0.001)$. Docosahexaenoic acid (22:6 $n-3)$ was negatively correlated $(r=-0.11, p<0.01)$, whereas eicosapentaenoic acid $(20: 5$ $n-3)$ was not ( $r=-0.02, \mathrm{NS})$. Most associations diminished or disappeared in lean individuals, indicating an effect of obesity.

Conclusions/interpretation Adipose tissue enriched with palmitic acid and depleted of essential PUFAs is associated with insulin resistance. The positive association between minor SFAs and insulin sensitivity merits further investigation.

Keywords Adipose tissue · Dietary fatty acids · Fatty acid composition $\cdot$ Insulin resistance $\cdot$ Insulin sensitivity

\begin{tabular}{ll}
\multicolumn{2}{l}{ Abbreviations } \\
ALA & $\alpha$-Linolenic acid \\
DHA & Docosahexaenoic acid \\
DNL & De novo lipogenesis \\
EPA & Eicosapentaenoic acid \\
GLC & Gas-liquid chromatography \\
HOMA-IR & HOMA of insulin resistance \\
LA & Linoleic acid \\
PUFA & Polyunsaturated fatty acid \\
SCD-1 & Stearoyl-CoA desaturase \\
SFA & Saturated fatty acid
\end{tabular}

\section{Introduction}

The incidence of insulin resistance is increasing worldwide and predisposes to type 2 diabetes and cardiovascular disease. Dietary fat quality, rather than quantity, has been 
suggested to influence insulin sensitivity [1]. However, the contribution of individual fatty acids to the regulation of insulin sensitivity is incompletely understood. Dietary $n-6$ polyunsaturated fatty acids (PUFAs) from vegetable sources have been linked to improved insulin sensitivity and reduced diabetes risk [2]. Linoleic acid (LA) in particular has been linked to improved glucose metabolism [2-4], although ambiguously [5]. In contrast, trans and saturated fatty acids (SFAs) have been associated with detrimental effects $[2,6,7]$. Yet, certain dietary SFAs have been suggested to also exhibit some beneficial physiological effects [8]. The marine fatty acids docosahexaenoic acid (DHA) and eicosapentaenoic acid (EPA) have been associated with diverse effects on glucose metabolism. Some studies have observed adverse associations to insulin sensitivity [5, 9-11], although other studies have not [12].

The imprecision of dietary questionnaires may in part explain the inconsistency in previous studies. It is well known that dietary assessment is hampered by underreporting and memory bias. Adipose tissue fatty acid composition is considered to be a reliable biomarker for long-term dietary intake of fatty acids [13, 14]. This is especially true for the essential fatty acids LA and $\alpha$ linolenic acid (ALA) and for DHA and EPA [15]. As renewal of fatty acids in adipose tissue is slow, its composition reflects dietary intake over $0.5-2$ years [13, $15,16]$. Another limitation of previous studies is the use of indirect measurements of insulin sensitivity, such as fasting insulin concentrations [17] or HOMA indices [18, 19].

We are not aware of any previous reports on the association between individual adipose tissue fatty acids and peripheral insulin sensitivity measured by the hyperinsulinaemic-euglycaemic clamp technique. Thus, we aimed to investigate the association between individual adipose tissue fatty acids and insulin sensitivity in a large community-based cohort of Swedish elderly men. We hypothesised that SFAs would be inversely correlated, whereas LA would be positively correlated with insulin sensitivity.

\section{Methods}

Between 1970 and 1973 all men born between 1920 and 1924 and living in Uppsala, Sweden, were invited to take part in a health survey with the aim of identifying risk factors for cardiovascular disease and type 2 diabetes in middle-aged men (Uppsala Longitudinal Study of Adult Men [ULSAM]; described in detail at www.pubcare.uu.se/ ULSAM, accessed 17 December 2009). Of these, 82\% ( $n=$ $2,322)$ participated in the investigation. The present analyses are based on the third examination cycle of the ULSAM cohort, when participants were approximately
71 years old (1991-1995, $n=1,221)$. Clamp measurements were performed, and on the same occasion the adipose tissue fatty acid composition was analysed in a subsample of 845 men. Laboratory analyses of the adipose tissue were performed on two occasions in the same laboratory and using similar methodology. In the first analysis, 316 samples were analysed for fatty acids 16:0, 16:1 n-7, 18:0, 18:1 n-9, 18:2 n-6, 18:3 n-6, 18:3 n-3, 20:3 n-6, 20:4 $n-6,20: 5 n-3,22: 4 n-6,22: 5 n-3$ and 22:6 n-3. In the second analysis, an additional 529 samples were analysed, this time also including fatty acids 12:0, 14:0, 15:0 and 17:0. The storage time between the two sessions was 13 17 years. The use of these two sample batches is unlikely to bias this study since they have been compared, i.e. they are similar with regard to relative fatty acid proportions, suggesting minimal oxidation of individual fatty acids, and the demographic data of the two subsamples were similar. Participants on medication for diabetes (orally or via injections, $n=35$ ) were excluded, as were those who did not undergo the clamp measurement $(n=15)$. Thus the present study sample comprises 795 men with available data on both insulin sensitivity and adipose tissue fatty acid composition. The study was approved by the Ethics Committee of Uppsala University. All participants provided written informed consent.

Adipose tissue fatty acids Subcutaneous adipose tissue was collected from the outer quadrant of the buttocks by biopsy $[20,21]$. The biopsy was taken with a needle coupled to a vacuum tube. The sample was collected in the connector between the needle and the tube, and stored at $-70^{\circ} \mathrm{C}$ in the connector until analysis. Prior to the fatty acid analysis the biopsy was weighed and homogenised. The amounts of fatty acids are given as the relative percentage of the sum of all fatty acids. The fatty acid compositions were analysed as described in detail by Boberg et al. [22]. Adipose tissue (5$25 \mathrm{mg}$ ) was extracted in $2.5 \mathrm{ml}$ methanol and $5.0 \mathrm{ml}$ chloroform (containing $0.005 \%$ [wt/vol.] butylated hydroxytoluene [BHT] as an antioxidant) and $7.5 \mathrm{ml} 0.2 \mathrm{~mol} / 1$ sodium dihydrogen phosphate $\left(\mathrm{NaH}_{2} \mathrm{PO}_{4}\right)$ was added and the extract was left at $4{ }^{\circ} \mathrm{C}$ overnight. The chloroform phase was evaporated to dryness under nitrogen and the lipid esters were transmethylated at $60^{\circ} \mathrm{C}$ overnight after addition of $2 \mathrm{ml}$ of $1 \mathrm{~mol} / \mathrm{l} \mathrm{H}_{2} \mathrm{SO}_{4}$ in methanol. The methyl esters were extracted into $3 \mathrm{ml}$ petroleum benzine containing $0.005 \%$ (wt/vol.) BHT after adding $1.5 \mathrm{ml}$ of distilled water. The phases were separated after thorough mixing and centrifugation at $1,500 \times \mathrm{g}$ for $10 \mathrm{~min}$. The petroleum benzine phase was pipetted off and the solvent was evaporated under nitrogen. The methyl esters were then redissolved in Uvasol grade hexane (Merck, Darmstadt, Germany). The fatty acid methyl esters were separated by gas-liquid chromatography (GLC) on a $30 \mathrm{~m}$ glass 
capillary column coated with Thermo TR-FAME (Thermo Electron Corporation, Franklin, MA, USA), with helium as carrier gas. An Agilent Technologies (Santa Clara, CA, USA) system consisting of a model GLC $6890 \mathrm{~N}$, autosampler 7683 and an Agilent ChemStation was used. The temperature was programmed to $150-260^{\circ} \mathrm{C}$. The fatty acids were identified by comparing each peak's retention time with fatty acid methyl ester standard $\mathrm{Nu}$ Check Prep (Elysian, MN, USA). For the first 319 samples, a different column was used (25 m Quadrex [Woodbridge, CT, USA] fused silica capillary column OV-351) and the temperature was lower $\left(130-220^{\circ} \mathrm{C}\right)$, as fewer fatty acids were included in the analysis; methodology was otherwise analogous, with similar validity.

Glucose metabolism Insulin sensitivity was determined by a hyperinsulinaemic-euglycaemic clamp procedure according to DeFronzo et al. [23], but slightly modified as described previously [24]; insulin was infused at a constant rate of $56 \mathrm{mU} \mathrm{min} \mathrm{m}^{-1} \mathrm{~m}^{-2}$. Insulin sensitivity $(M)$ was calculated as glucose infusion rate $\left(\mu \mathrm{mol} \mathrm{kg} \mathrm{kgin}^{-1}\right)$ during the last $60 \mathrm{~min}$ of the $2 \mathrm{~h}$ clamp. HOMA of insulin resistance (HOMA-IR) was calculated as described by Matthews et al. [25].

Dietary assessment Dietary assessment was performed as a 7 day dietary record, using an optically readable form. A subset of 1,138 men recorded their dietary intake during seven consecutive days. The food record used was a precoded menu book, prepared and previously used by the National Food Administration and Statistics Sweden in a food survey of 3,000 households in 1989 [26]. The questionnaire has been validated in different populations $[26,27]$. Data on dietary intake were analysed for correlations with adipose tissue proportions for select fatty acids.

Statistics Normally distributed results are presented as means $\pm \mathrm{SD}$, skewed results are presented as median (interquartile range). For normally distributed variables, parametric testing was used, with pair-wise correlations presented as Pearson's correlation coefficients. Log transformation $\left(\log _{e}\right)$ was performed to achieve normal distribution for skewed $(W<0.95$ in the Shapiro-Wilks test) variables (12:0, 18:2 $n-6,18: 3 n-6,20: 3 n-6,20: 5 n-3,22: 4$ $n-6,22: 5 n-3,22: 6 n-3$, alcohol intake and HOMA-IR). The $\beta$-coefficients were not standardised. BMI was calculated as weight $(\mathrm{kg}) /$ height $(\mathrm{m})^{2}$. Smoking was considered a categorical variable (non-smoker/former smoker $=0$, smoker $=1$ ). Physical activity levels were graded from 1 (lowest) to 4 (highest) on an arbitrary ordinal scale. Alcohol intake was assessed from the 7 day dietary record as $\mathrm{g} / \mathrm{day}$.
In addition, for the most important findings (16:0, LA and ALA) we performed tests for effect modification on the two different analyses occasions by including multiplicative interaction terms with these select fatty acids and the first or second fatty acid analysis. None of the interaction terms reached statistical significance ( $p>0.25$ for all), arguing against a potential influence of differences in analytic procedures or freezer time on the results. Accordingly, all available samples were included in presented data to maximise statistical power. $p$ values $<0.05$ were considered statistically significant. Analyses were performed using JMP version 3.2 (SAS Institute, Cary, NC, USA) and Intercooled STATA 10.0 for Windows (Stata Corporation, College Station, TX, USA) software.

\section{Results}

The baseline characteristics of the study sample of men with available data from both clamp and adipose tissue biopsies $(n=795)$ are shown in Table 1. Participants were slightly overweight (BMI $26.3 \pm 3.4 \mathrm{~kg} / \mathrm{m}^{2}$ ) and metabolic risk factors were modestly elevated (Table 1 ). The original sample of men investigated at age $71(n=1,221)$ and the subsample of men whose biopsies were included in the second laboratory analysis $(n=506)$ showed little discrepancy compared with the study sample (data not shown), thereby supporting the generalisability of the results.

The major fatty acids in adipose tissue samples were oleic acid (18:1 n-9, 49\%), palmitic acid (16:0, 22\%), LA (18:2 $n-6,12 \%)$ and palmitoleic acid $(16: 1 n-7,7 \%)$, thus making up $90 \%$ of total fatty acids. Palmitic acid was the major SFA, followed by stearic (18:0, 4\%), myristic (14:0, $3 \%)$, lauric $(12: 0,0.5 \%)$, pentadecanoic $(15: 0,0.3 \%)$ and margaric $(17: 0,0.2 \%)$ acid. Proportions were similar in the two samples and comparable with those seen in other populations $[13,16]$ (Table 1).

Univariate correlations between insulin sensitivity and individual fatty acids in adipose tissue are shown in Table 2. Among SFAs, only 16:0 was negatively correlated with insulin sensitivity $(r=-0.14)$, as was its desaturation product 16:1 $n-7$ ( $r=-0.15)$. Conversely, 12:0, 18:0, 14:0 and 17:0 were positively correlated $(r=0.46,0.41,0.32$ and 0.21 , respectively). Very-long-chain $n-6$ fatty acids, i.e. those with $\geq 20$ carbon atoms, correlated negatively with insulin sensitivity. For essential PUFAs, correlations were positive $(r=0.10$ for LA and $r=0.16$ for ALA). The correlation was negative for DHA (22:6 n-3), but no significant correlation was observed for EPA (20:5 n-3) (Table 2).

Multivariate regression analyses, adjusting for BMI, smoking, alcohol intake and physical activity are also 
Table 1 Baseline characteristics of the study sample $(n=795)^{\mathrm{a}}$

\begin{tabular}{|c|c|}
\hline Characteristic & $\begin{array}{l}\text { Value (mean } \pm \mathrm{SD} \\
\left.\text { or median }[\mathrm{IQR}]^{\mathrm{b}}\right)\end{array}$ \\
\hline Insulin sensitivity $\left(\mu \mathrm{mol} \mathrm{kg} \mathrm{kg}^{-1} \min ^{-1}\right)$ & $28.6 \pm 10.8$ \\
\hline Waist circumference $(\mathrm{cm})$ & $94.8 \pm 9.5$ \\
\hline BMI $\left(\mathrm{kg} / \mathrm{m}^{2}\right)$ & $26.4 \pm 3.4$ \\
\hline Triacylglycerol $(\mathrm{mmol} / \mathrm{l})^{\mathrm{b}}$ & $1.3(0.9-1.7)$ \\
\hline HDL-cholesterol $(\mathrm{mmol} / \mathrm{l})^{\mathrm{b}}$ & $1.2(1.0-1.5)$ \\
\hline Fasting plasma glucose $(\mathrm{mmol} / \mathrm{l})^{\mathrm{b}}$ & $5.4(5.0-5.9)$ \\
\hline Systolic blood pressure $(\mathrm{mmHg})$ & $146.9 \pm 18.6$ \\
\hline Lauric acid $(12: 0)^{\mathrm{a}, \mathrm{b}, \mathrm{c}}$ & $0.50(0.40-0.62)$ \\
\hline Myristic acid $(14: 0)^{\mathrm{a}, \mathrm{c}}$ & $3.4 \pm 0.6$ \\
\hline Pentadecanoic acid $(15: 0)^{\mathrm{a}, \mathrm{c}}$ & $0.34 \pm 0.07$ \\
\hline Palmitic acid $(16: 0)^{\mathrm{c}}$ & $21.8 \pm 2.0$ \\
\hline Palmitoleic acid $(16: 1 n-7)^{\mathrm{c}}$ & $6.8 \pm 1.7$ \\
\hline Margaric acid $(17: 0)^{\mathrm{a}, \mathrm{c}}$ & $0.23 \pm 0.04$ \\
\hline Stearic acid $(18: 0)^{\mathrm{c}}$ & $4.0 \pm 1.0$ \\
\hline Oleic acid $(18: 1 n-9)^{\mathrm{c}}$ & $49.3 \pm 2.3$ \\
\hline LA $(18: 2 n-6)^{\mathrm{b}, \mathrm{c}}$ & $12.4(10.9-14.1)$ \\
\hline$\gamma$-Linolenic acid $(18: 3 n-6)^{\mathrm{b}, \mathrm{c}}$ & $0.09(0.07-0.11)$ \\
\hline $\operatorname{ALA}(18: 3 n-3)^{\mathrm{c}}$ & $1.0 \pm 0.2$ \\
\hline Dihomo- $\gamma$-linolenic acid $(20: 3 n-6)^{\mathrm{b}, \mathrm{c}}$ & $0.16(0.13-0.20)$ \\
\hline Arachidonic acid $(20: 4 n-6)^{\mathrm{c}}$ & $0.35 \pm 0.10$ \\
\hline EPA $(20: 5 n-3)^{\mathrm{b}, \mathrm{c}}$ & $0.14(0.11-0.18)$ \\
\hline Docosatetraenoic acid $(22: 4 n-6)^{\mathrm{b}, \mathrm{c}}$ & $0.11(0.09-0.14)$ \\
\hline Docosapentaenoic acid $(22: 5 n-3)^{\mathrm{b}, \mathrm{c}}$ & $0.27(0.22-0.33)$ \\
\hline DHA $(22: 6 n-3)^{\mathrm{b}, \mathrm{c}}$ & $0.30(0.24-0.41)$ \\
\hline
\end{tabular}

${ }^{\mathrm{a}}$ For 12:0, 14:0, 15:0 and 17:0, sample sizes were smaller $(n=506)$, as these fatty acids were not included in the first laboratory analysis

${ }^{\mathrm{b}}$ Skewed distributed variables are presented as median (interquartile range [IQR])

${ }^{\mathrm{c}}$ Fatty acids are presented as percentages of total in adipose tissue

shown in Table 2. Here, the sample size was somewhat smaller $(n=719)$, owing to missing data on covariates. The dependent variable was insulin sensitivity ( $M$ value) as measured by the clamp. Overall, a pattern similar to univariate analyses was observed (Table 2). Again, 16:0 and 16:1 n-7 were negatively related to insulin sensitivity. Lauric acid (12:0), 18:0, 14:0 and 17:0 had significantly positive regression coefficients, especially noticeable for 12:0 and for 17:0, although for 17:0 it was not highly significant (Table 2). All long-chain $n-6$ fatty acids showed negative regression coefficients. LA and ALA showed positive regression coefficients, but for LA this was no longer significant $(p=0.15)$. For EPA and DHA, no significant associations were observed (Table 2).

Analyses of associations between adipose tissue fatty acids and HOMA-IR as an indirect measure of insulin resistance were performed to increase validity (Table 2). In both univariate and multivariate analyses, most associations with HOMA-IR corresponded well with those with the euglycaemic clamp. An exception was LA, more strongly inversely associated $(p<0.001)$ with insulin resistance by HOMA than positively associated with insulin sensitivity by the clamp $(p=0.15)$ in multivariate analyses. In a separate regression analysis, adjusting for BMI only, results differed only very slightly (data not shown). However, an interaction analysis showed a significant interaction between 12:0 and BMI $(p=0.005)$. Thus, further secondary analyses were performed, stratifying the sample into lean (BMI $<25 \mathrm{~kg} / \mathrm{m}^{2}$ ) and overweight (BMI $>25 \mathrm{~kg} / \mathrm{m}^{2}$ ) men (Table 3). In overweight men, associations were similar to those of the whole study sample. In lean men, however, only 12:0, 18:0 and ALA remained positively correlated with insulin sensitivity, while 16:1 n-7, 20:3 n-6, 20:4 n-6, 22:4 n-6 and 22:5 n-3 were negatively correlated with insulin sensitivity (Table 3 ).

Dietary record data Correlations between adipose tissue fatty acid proportions and dietary record data of corresponding fatty acids $(\mathrm{g} /$ day $)$ were significant $(p<0.001)$ for 12:0 $(r=0.18)$, 14:0 $(r=0.38), 16: 0(r=0.22), 18: 0 \quad(r=0.14)$, LA $(r=0.16)$, ALA $(r=0.16)$, EPA $(r=0.23)$ and DHA $(r=0.29)$, but not for oleic acid $(18: 1 n-9, p=0.35)$. For palmitoleic acid $(16: 1 n-7)$, the correlation was weak $(r=0.13)$ but significant $(p=0.03)$. Also, 16:1 n-7 in adipose tissue was weakly correlated to dietary 16:0 $(r=0.08, p=0.02)$.

Since we found particularly strong correlations between adipose tissue 14:0 and reported intake we further explored potential food sources for this fatty acid. Adipose tissue 14:0 was correlated with total dietary SFAs $(r=0.32, p<$ $0.001)$ and inversely with meat intake $(r=-0.14, p=0.003)$, but no correlation was found with dairy products $(r=0.03$, $p=0.64$ ).

Since the strongest correlation with insulin sensitivity was found for 12:0, we further examined potential food sources for this fatty acid. Adipose tissue 12:0 was correlated with consumption of spreads $(r=0.12, p<0.01)$, but not with milk $(r=0.03, p=0.54)$. It was negatively correlated with meat consumption $(r=-0.14, p=0.002)$ and alcohol intake $(r=-0.16, p<0.001)$. Finally, fatty acid correlations with physical activity were analysed showing 12:0 to be the fatty acid most closely correlated with physical activity $(r=0.19, p<0.001)$.

\section{Discussion}

This large cross-sectional study of elderly men was undertaken to elucidate the relationships between adipose tissue fatty acid composition and insulin sensitivity measured directly by a euglycaemic clamp. The major SFA, 
Table 2 Crude correlations and multivariate ${ }^{\mathrm{a}}$ regression analyses of adipose tissue fatty acids with insulin sensitivity measured by the euglycaemic clamp and HOMA-IR ${ }^{\mathrm{b}}$

\begin{tabular}{|c|c|c|c|c|}
\hline \multirow[t]{2}{*}{ Fatty acid } & \multicolumn{2}{|c|}{ Crude correlation coefficient $(r)$} & \multicolumn{2}{|c|}{ Multivariate regression analyses, $\beta$-coefficient $(95 \% \mathrm{CI})$} \\
\hline & Insulin sensitivity $(M)$ & HOMA-IR ${ }^{b}$ & Insulin sensitivity $(M)$ & HOMA-IR ${ }^{b}$ \\
\hline $12: 0^{\mathrm{b}}$ & $0.46^{* * *}$ & $-0.43 * * *$ & $1.3(0.8,1.7)^{* * *}$ & $-0.38(-0.52,-0.24)^{* * *}$ \\
\hline 14:0 & $0.32 * * *$ & $-0.27 * * *$ & $0.35(0.11,0.59)^{* *}$ & $-0.10(-0.17,-0.02)^{*}$ \\
\hline $15: 0$ & 0.07 & -0.04 & $0.04(-1.9,2.0)$ & $0.10(-0.54,0.74)$ \\
\hline $16: 0$ & $-0.14 * * *$ & $0.16^{* * *}$ & $-0.09(-0.15,-0.03)^{* *}$ & $0.03(0.02,0.05)^{* * *}$ \\
\hline $16: 1 n-7$ & $-0.15^{* * *}$ & $0.14 * * *$ & $-0.07(-0.14,-0.006)^{*}$ & $0.03(0.006,0.05)^{* *}$ \\
\hline $17: 0$ & $0.21 * * *$ & $-0.21 * * *$ & $3.5(0.3,6.6)^{*}$ & $-1.4(-2.4,-0.3)^{* * *}$ \\
\hline 18:0 & $0.41 * * *$ & $-0.35 * * *$ & $0.42(0.30,0.54)^{* * *}$ & $-0.12(-0.16,-0.08)^{* * *}$ \\
\hline $18: 1 n-9$ & -0.03 & -0.01 & $0.06(0.01,0.11)^{*}$ & $-0.02(-0.04,-0.005)^{* *}$ \\
\hline $18: 2 n-6^{\mathrm{b}}$ & $0.10 * *$ & $-0.19 * * *$ & $0.40(-0.15,0.94)$ & $-0.43(-0.60,-0.25)^{* * *}$ \\
\hline $18: 3 n-6^{\mathrm{b}}$ & 0.02 & -0.04 & $-0.13(-0.41,0.15)$ & $0.02(-0.08,0.11)$ \\
\hline $18: 3 n-3$ & $0.16^{* * *}$ & $-0.23 * * *$ & $1.0(0.5,1.5)^{* * *}$ & $-0.49(-0.66,-0.33)^{* * *}$ \\
\hline $20: 3 n-6^{\mathrm{b}}$ & $-0.31 * * *$ & $0.15^{* * *}$ & $-0.86(-1.2,-0.48)^{* * *}$ & $0.03(-0.10,0.16)$ \\
\hline $20: 4 n-6$ & $-0.38 * * *$ & $0.22 * * *$ & $-3.8(-5.0,-2.7) * * *$ & $0.43(0.03,0.82)^{*}$ \\
\hline $20: 5 n-3^{\mathrm{b}}$ & -0.02 & 0.04 & $-0.02(-0.36,0.33)$ & $0.02(-0.09,0.13)$ \\
\hline $22: 4 n-6^{\mathrm{b}}$ & $-0.37 * * *$ & $0.26^{* * *}$ & $-1.1(-1.6,-0.7)^{* * *}$ & $0.19(0.06,0.33)^{* *}$ \\
\hline $22: 5 n-3^{\mathrm{b}}$ & $-0.24 * * *$ & $0.11 * *$ & $-0.70(-1.1,-0.30)^{* * *}$ & $-0.01(-0.14,0.11)$ \\
\hline $22: 6 n-3^{\mathrm{b}}$ & $-0.11 * *$ & 0.03 & $-0.17(-0.46,0.12)$ & $-0.07(-0.17,0.02)$ \\
\hline
\end{tabular}

${ }^{\text {a }}$ Adjusted for BMI, smoking, alcohol intake and physical activity

${ }^{\mathrm{b}}$ Data for 12:0, 18:2 n-6, 18:3 n-6, 20:3 n-6, 20:5 n-3, 22:4 n-6, 22:5 n-3, 22:6 n-3 and HOMA-IR were $\log _{e}$ transformed because of skewed distribution

${ }^{*} p<0.05, * * p<0.01, * * * p<0.001$

palmitic acid (16:0), and its desaturation product palmitoleic acid (16:1 n-7), were negatively associated with insulin sensitivity. The essential PUFAs, i.e. LA and ALA, were positively associated with insulin sensitivity, although for LA, this association was not significant after adjusting for lifestyle covariates. Very-long-chain $n-6$ fatty acids were negatively correlated with insulin sensitivity. This was expected [1] and mainly reflects endogenous $n-6$ fatty acid synthesis, since LA is the only $n-6$ fatty acid whose content in adipose tissue reliably reflects dietary intake [14]. Marine very-long-chain $n$-3 fatty acids were either not associated (EPA) or showed an inverse association (DHA) with insulin sensitivity in univariate analyses, a finding also compatible with recent literature [2], including an intervention with fish oil where insulin sensitivity was measured by the clamp method [3]. The strong, positive correlations between insulin sensitivity and minor SFAs including 18:0, 14:0 and especially 12:0 were somewhat unexpected and warrant further consideration.

Our study has limitations. As an observational study, conclusions about causality cannot be drawn. Amounts of fatty acids in samples were expressed as proportions of total fatty acids, i.e. relative, rather than absolute values. Thus, a high proportion of SFAs will, to a varying extent, result in low percentage of unsaturated fatty acids owing to the interdependent relationship between the fatty acids. Thus, it is difficult to interpret the impact of a single fatty acid independently of other fatty acids. Further, only elderly white men are studied, which limits external validity. As noted, adipose tissue GLC analyses were performed at two separate occasions. However, methodology and its validity were similar on both occasions. An interaction analysis was made for the key findings, arguing against a storage effect between the two subsamples. Fatty acids 12:0, 14:0, 15:0 and 17:0 were included only in the second GLC analysis. However, relative amounts of different fatty acids were similar in both samples. Strengths of the study are that we used a euglycaemic clamp technique for insulin sensitivity and adipose tissue composition for long-term dietary fatty acid intake. The sample size is large and the study is population based. Similar studies are scarce; none of this magnitude has to the best of our knowledge been performed previously.

In adipose tissue, proportions of the essential PUFAs LA and ALA are valid biomarkers of dietary intake [13-15]. Dietary sources in this population include margarines, vegetable oils and nuts, foods associated with lower diabetes risk [2]. In the early 1990s, commercial margarines 
Table 3 Crude associations $(r)$ between adipose tissue fatty acids and insulin sensitivity stratified in lean and overweight individuals

\begin{tabular}{|c|c|c|}
\hline \multirow[t]{2}{*}{ Fatty acid } & \multicolumn{2}{|l|}{ BMI $\left(\mathrm{kg} / \mathrm{m}^{2}\right)$} \\
\hline & $<25\left(n=167-282^{\mathrm{a}}\right)$ & $>25\left(n=339-513^{\mathrm{a}}\right)$ \\
\hline $12: 0^{\mathrm{b}}$ & $0.21^{* *}$ & $0.43^{* * *}$ \\
\hline $14: 0$ & 0.15 & $0.28 * * *$ \\
\hline $15: 0$ & 0.01 & 0.07 \\
\hline $16: 0$ & -0.05 & $-0.15 * * *$ \\
\hline $16: 1 n-7$ & $-0.12 *$ & $-0.14 * *$ \\
\hline $17: 0$ & 0.10 & $0.21 * * *$ \\
\hline 18:0 & $0.32 * * *$ & $0.32 * * *$ \\
\hline $18: 1 n-9$ & -0.00 & 0.03 \\
\hline $18: 2 n-6^{\mathrm{b}}$ & 0.03 & $0.10^{*}$ \\
\hline $18: 3 n-6^{\mathrm{b}}$ & -0.04 & 0.01 \\
\hline $18: 3 n-3$ & $0.13 *$ & $0.16^{* * *}$ \\
\hline $20: 3 n-6^{\mathrm{b}}$ & $-0.18^{* *}$ & $-0.30 * * *$ \\
\hline $20: 4 n-6$ & $-0.37 * * *$ & $-0.32 * * *$ \\
\hline $20: 5 n-3^{b}$ & 0.01 & -0.05 \\
\hline $22: 4 n-6^{\mathrm{b}}$ & $-0.29 * * *$ & $-0.33 * * *$ \\
\hline $22: 5 n-3^{b}$ & $-0.14^{*}$ & $-0.21 * * *$ \\
\hline $22: 6 n-3^{\mathrm{b}}$ & -0.02 & $-0.11^{*}$ \\
\hline
\end{tabular}

${ }^{\text {a }}$ Sample sizes differ because of the two different analysis occasions

${ }^{\mathrm{b}}$ Data for 12:0, 18:2 n-6 (BMI $<25 \mathrm{~kg} / \mathrm{m}^{2}$ ), 18:3 n-6, 20:3 n-6 $\left(\right.$ BMI $\left.>25 \mathrm{~kg} / \mathrm{m}^{2}\right), 20: 5 n-3,22: 4 n-6,22: 5 n-3$, and 22:6 n-3 were $\log _{e}$ transformed because of skewed distribution

$* p<0.05, * * p<0.01, * * * p<0.001$

in Sweden contained trans fats, possibly underestimating beneficial effects of dietary $n-6$ PUFAs on insulin sensitivity [4, 28]. Notably, in multivariate analysis a highly significant inverse association was found between LA and HOMA-IR $(p<0.001)$, while between LA and clampderived insulin sensitivity the association was not significant (Table 2). This suggests a positive relationship between adipose tissue LA and hepatic insulin sensitivity, rather than with peripheral insulin sensitivity as reflected by the clamp. However, a previous controlled intervention study showed improved peripheral insulin sensitivity by a clamp after an LA-rich diet [4], indicating possible beneficial effects not only on hepatic glucose metabolism.

For many fatty acids in our study, correlations with dietary intakes were low in comparison with earlier studies [13-15]. The positive association between 14:0 and insulin sensitivity may imply a favourable role of dairy intake on glucose metabolism, as suggested in some observational studies [2]. However, if this were the case, one would expect a similar pattern for 15:0 and 17:0, also considered closely associated with dairy intake when measured in serum [29] or erythrocyte membranes [30]. For 15:0, this was not significant in our study, suggesting that other dietary sources of 14:0, or endogenous metabolism, may contribute to the association, as also recently suggested by Roberts et al. [19]. The positive association between 18:0 and insulin sensitivity also accord with that study, in which adipose tissue 14:0 and 18:0 were positively associated with HOMA insulin sensitivity, whereas 16:0 was inversely correlated in a group of 59 healthy individuals. The positive association between $14: 0$ and 18:0 and insulin sensitivity was suggested to mainly reflect de novo lipogenesis (DNL), since no correlation was seen between SFA intake and adipose tissue content of these fatty acids [19]. In our larger population study, we did, however, observe significant but weak associations between dietary SFA intake and adipose tissue SFAs. However, in agreement with Roberts et al., major SFA food sources such as milk products and meat intake were not significantly associated with either 14:0 or 12:0 in our study. There was even an inverse association between meat intake and both of these fatty acids, and also between alcohol intake and 12:0. Whether carbohydrate intake may partly contribute to increased SFA proportions could also be considered, although there is little evidence to support this [19] and adipose tissue DNL seems to be minor in Western populations [31], including Sweden, consuming $\sim 45 \%$ of energy as carbohydrate in 1989 [26]. It was further suggested by Roberts et al. that the relationship between SFAs and insulin sensitivity may be stronger in lean individuals, partly because of smaller adipocyte size and lipogenesis [19]. However, in our secondary analyses, stratified by BMI, we could not observe this in our elderly Swedish population. Further studies should investigate whether adipocyte size and insulin resistance per se may influence adipose tissue fatty acid composition. This is especially relevant since several of the key associations could not be observed in lean individuals, thus suggesting an effect of obesity on the associations. Another study on adipose tissue fatty acids and HOMA index showed a higher 18:1 n-9/18:0 ratio in insulin-resistant individuals [32]. The ratio 18:1 n-9/18:0 also reflected mRNA expression of stearoyl-CoA desaturase (SCD-1) [32]. Those results and ours indirectly support the recent proposal by Roberts et al. that 18:0 may be the key determinant of the 18:1 $n-9 / 18: 0$ ratio in adipose tissue, which is in turn inversely associated with insulin sensitivity.

Regarding lauric acid (12:0), plausible dietary sources include spreads, milk and coconut oil. We found no correlation of adipose tissue 12:0 with intake of dairy products. Coconut oil intake could possibly account for part of the intake, as it is included in various bakery products, chocolate and sweets, and some spreads, perhaps not fully matched by the dietary recordings. It should be noted that vegetable spreads and margarines contain significant amounts of 12:0 in Sweden [33]. Also, 12:0 is considered a medium-chain SFA, and does as such possess different metabolic qualities from longer-chain fatty acids. For 
instance, 12:0 is more readily oxidised in adipose tissue [34, 35], possibly distorting the relationship between dietary intake and adipose tissue composition. Also, there is selectivity in how efficiently different dietary fatty acids are stored in adipose tissue [36]. Physical activity may also confound the link between 12:0 and insulin sensitivity, especially considering a 4 week controlled study showing no improvement of insulin sensitivity after a diet rich in 12:0 vs 16:0 [37]. Physical activity has been shown to affect adipose tissue composition, elevating 12:0, 14:0, 18:0 and LA; but reducing 16:0 and 18:1 n-9 [38]. However, although 12:0 in particular was associated with physical activity in our study, this was adjusted for in regression analyses with minimal effect on results. In skeletal muscle phospholipids of physically active individuals, the proportion of $16: 0$ is lower, whereas elongase activity converting 16:0 to 18:0 seems higher [39]. Taken together, these relationships suggest that higher proportions of minor SFAs in adipose tissue may be markers of a healthy lifestyle, or in any case, of a healthy metabolic state. It must also be considered that insulin sensitivity per se may influence adipose tissue fatty acid composition, as insulin affects several enzymes involved in fat storage and fatty acid metabolism [39]. For instance, insulin-sensitising drugs may increase SCD-1 activity and gene expression in adipose tissue [40].

We have not found any convincing evidence in the literature showing potential insulin-sensitising effects of these minor SFAs. In contrast, several, but not all observational and interventional studies indicate that dietary SFAs, when substituted for monounsaturated fatty acids or PUFAs, impair insulin action measured by IVGTTs [7] or the clamp methods $[2,4]$.

Potential mechanisms for effects of fatty acids on insulin sensitivity include altered structural properties of cell membranes, direct regulatory effects on gene expression, and direct effects on insulin-sensitive tissues [2]. Experimental studies also suggest that Toll-like receptors can be a link between fatty acids, inflammation and insulin resistance $[2,41]$.

For reasons noted earlier, these results must be interpreted with caution with respect to dietary recommendations. However, as adipose tissue fatty acid composition reflects long-term dietary intake of certain fatty acids, our results may have implications in the long-term perspective and can add knowledge to short-term intervention studies on dietary fatty acids and insulin-sensitivity by clamp [4] or IVGTT [37] methods.

In conclusion, the positive associations between insulin sensitivity and minor SFAs in adipose tissue is of interest, but may reflect factors other than dietary intake, e.g. DNL and/or being markers of a healthy lifestyle. Nevertheless, the diverse associations between individual SFAs and insulin sensitivity do raise the question whether SFAs should be regarded as a heterogeneous group concerning insulin action. Overall, the results are compatible with current dietary recommendations, e.g. to limit intakes of palmitic acid while maintaining sufficient amounts of essential PUFAs.

Acknowledgements The skilful laboratory assistance of S. Tengblad (Department of Public Health and Caring Sciences, Clinical Nutrition and Metabolism, Uppsala University, Sweden) is gratefully acknowledged. D. Iggman was funded by the Center for Clinical Research Dalarna and was supported by a grant from Swedish Nutrition Foundation. U. Risérus was funded by NordForsk (Nordic Centre of Excellence in Food, Nutrition and Health, SYSDIET) and the Swedish Research Council for Working Life and Social Sciences.

Duality of interest The authors declare that there is no duality of interest associated with this manuscript.

\section{References}

1. Riserus U (2008) Fatty acids and insulin sensitivity. Curr Opin Clin Nutr Metab Care 11:100-105

2. Riserus U, Willett WC, Hu FB (2009) Dietary fats and prevention of type 2 diabetes. Prog Lipid Res 48:44-51

3. Mostad IL, Bjerve KS, Bjorgaas MR, Lydersen S, Grill V (2006) Effects of $n-3$ fatty acids in subjects with type 2 diabetes: reduction of insulin sensitivity and time-dependent alteration from carbohydrate to fat oxidation. Am J Clin Nutr 84:540-550

4. Summers LK, Fielding BA, Bradshaw HA et al (2002) Substituting dietary saturated fat with polyunsaturated fat changes abdominal fat distribution and improves insulin sensitivity. Diabetologia 45:369-377

5. Borkman M, Chisholm DJ, Furler SM et al (1989) Effects of fish oil supplementation on glucose and lipid metabolism in NIDDM. Diabetes 38:1314-1319

6. Kinsell LW, Walker G, Michaels GD, Olson FE (1959) Dietary fats and the diabetic patient. N Engl J Med 261:431-434

7. Vessby B, Unsitupa M, Hermansen K et al (2001) Substituting dietary saturated for monounsaturated fat impairs insulin sensitivity in healthy men and women: the KANWU Study. Diabetologia 44:312-319

8. Rioux V, Legrand P (2007) Saturated fatty acids: simple molecular structures with complex cellular functions. Curr Opin Clin Nutr Metab Care 10:752-758

9. Vessby B, Boberg M (1990) Dietary supplementation with $n-3$ fatty acids may impair glucose homeostasis in patients with noninsulin-dependent diabetes mellitus. J Intern Med 228:165-171

10. Friday KE, Childs MT, Tsunehara CH, Fujimoto WY, Bierman EL, Ensinck JW (1989) Elevated plasma glucose and lowered triglyceride levels from omega-3 fatty acid supplementation in type II diabetes. Diabetes Care 12:276-281

11. Kaushik M, Mozaffarian D, Spiegelman D, Manson JE, Willett WC, Hu FB (2009) Long-chain omega-3 fatty acids, fish intake, and the risk of type 2 diabetes mellitus. Am J Clin Nutr 90:613620

12. Kabir M, Skurnik G, Naour N et al (2007) Treatment for 2 mo with $n-3$ polyunsaturated fatty acids reduces adiposity and some atherogenic factors but does not improve insulin sensitivity in women with type 2 diabetes: a randomized controlled study. Am J Clin Nutr 86:1670-1679 
13. Hodson L, Skeaff CM, Fielding BA (2008) Fatty acid composition of adipose tissue and blood in humans and its use as a biomarker of dietary intake. Prog Lipid Res 47:348-380

14. Baylin A, Kabagambe EK, Siles X, Campos H (2002) Adipose tissue biomarkers of fatty acid intake. Am J Clin Nutr 76:750-757

15. Cantwell MM (2000) Assessment of individual fatty acid intake. Proc Nutr Soc 59:187-191

16. Field C (1984) Modulation of adipose tissue fat composition by diet: a review. Nutr Res 4:743-755

17. Laaksonen DE, Lakka TA, Lakka HM et al (2002) Serum fatty acid composition predicts development of impaired fasting glycaemia and diabetes in middle-aged men. Diabet Med 19:456-464

18. Feskens EJ, Loeber JG, Kromhout D (1994) Diet and physical activity as determinants of hyperinsulinemia: the Zutphen Elderly Study. Am J Epidemiol 140:350-360

19. Roberts R, Hodson L, Dennis AL et al (2009) Markers of de novo lipogenesis in adipose tissue: associations with small adipocytes and insulin sensitivity in humans. Diabetologia 52:882-890

20. Hirsch J, Farquhar JW, Ahrens EH Jr, Peterson ML, Stoffel W (1960) Studies of adipose tissue in man. A microtechnic for sampling and analysis. Am J Clin Nutr 8:499-511

21. Beynen AC, Katan MB (1985) Rapid sampling and long-term storage of subcutaneous adipose-tissue biopsies for determination of fatty acid composition. Am J Clin Nutr 42:317-322

22. Boberg M, Vessby B, Croon LB (1985) Fatty acid composition of platelets and of plasma lipid esters in relation to platelet function in patients with ischaemic heart disease. Atherosclerosis 58:49-63

23. DeFronzo RA, Tobin JD, Andres R (1979) Glucose clamp technique: a method for quantifying insulin secretion and resistance. Am J Physiol 237:E214-E223

24. Pollare T, Lithell H, Selinus I, Berne C (1988) Application of prazosin is associated with an increase of insulin sensitivity in obese patients with hypertension. Diabetologia 31:415-420

25. Matthews DR, Hosker JP, Rudenski AS, Naylor BA, Treacher DF, Turner RC (1985) Homeostasis model assessment: insulin resistance and beta-cell function from fasting plasma glucose and insulin concentrations in man. Diabetologia 28:412-419

26. Becker W (ed) (1994) Befolkningens kostvanor och näringsintag i Sverige 1989. Metod och resultatanalys [Dietary habits and nutrient intake in Sweden 1989. Methods and analysis; in Swedish, English summary]. Nutritional Unit, Swedish National Food Administration, Uppsala, Sweden

27. Becker W, Lennernäs M, Gustafsson I-B et al (1998) Precoded food records compared with weighed food records for measuring dietary habits in a population of Swedish adults. Food Nutr Res 42:145-149

28. Heine RJ, Mulder C, Popp-Snijders C, van der Meer J, van der Veen EA (1989) Linoleic-acid-enriched diet: long-term effects on serum lipoprotein and apolipoprotein concentrations and insulin sensitivity in noninsulin-dependent diabetic patients. Am J Clin Nutr 49:448-456

29. Smedman AE, Gustafsson IB, Berglund LG, Vessby BO (1999) Pentadecanoic acid in serum as a marker for intake of milk fat: relations between intake of milk fat and metabolic risk factors. Am J Clin Nutr 69:22-29

30. Wennberg M, Vessby B, Johansson I (2009) Evaluation of relative intake of fatty acids according to the Northern Sweden FFQ with fatty acid levels in erythrocyte membranes as biomarkers. Public Health Nutr 12:1477-1484

31. Strawford A, Antelo F, Christiansen M, Hellerstein MK (2004) Adipose tissue triglyceride turnover, de novo lipogenesis, and cell proliferation in humans measured with ${ }^{2} \mathrm{H}_{2} \mathrm{O}$. Am J Physiol Endocrinol Metab 286:E577-E588

32. Sjogren P, Sierra-Johnson J, Gertow K et al (2008) Fatty acid desaturases in human adipose tissue: relationships between gene expression, desaturation indexes and insulin resistance. Diabetologia 51:328-335

33. Livsmedelsverkets livsmedelsdatabas. Swedish National Food administration. Available from http://www.slv.se/sv/grupp1/Mat-och-naring/ Vad-innehaller-maten/Livsmedelsdatabasen-/, accessed 10 May 2009

34. Forsyth JH, Karmarkar J, Hegsted DH (1968) Deposition and mobilization of fatty acids in adipose tissue. Metabolism 17:502-514

35. DeLany JP, Windhauser MM, Champagne CM, Bray GA (2000) Differential oxidation of individual dietary fatty acids in humans. Am J Clin Nutr 72:905-911

36. Summers LK, Barnes SC, Fielding BA et al (2000) Uptake of individual fatty acids into adipose tissue in relation to their presence in the diet. Am J Clin Nutr 71:1470-1477

37. Schwab US, Niskanen LK, Maliranta HM, Savolainen MJ, Kesaniemi YA, Uusitupa MI (1995) Lauric and palmitic acidenriched diets have minimal impact on serum lipid and lipoprotein concentrations and glucose metabolism in healthy young women. J Nutr 125:466-473

38. Sutherland WH, Woodhouse SP, Heyworth MR (1981) Physical training and adipose tissue fatty acid composition in men. Metabolism 30:839-844

39. Vessby B, Gustafsson IB, Tengblad S, Boberg M, Andersson A (2002) Desaturation and elongation of fatty acids and insulin action. Ann N Y Acad Sci 967:183-195

40. Riserus U, Tan GD, Fielding BA et al (2005) Rosiglitazone increases indexes of stearoyl-CoA desaturase activity in humans: link to insulin sensitization and the role of dominant-negative mutation in peroxisome proliferator-activated receptor-gamma. Diabetes 54:1379-1384

41. Kim JK (2006) Fat uses a TOLL-road to connect inflammation and diabetes. Cell Metab 4:417-419 